\title{
MANEJ O DA DOR PÓS-OPERATÓRIA NA VISÃO DOS PAIS DA CRIANÇA HOSPITALIZADA
}

\author{
El manej o del dolor post-operatorio en la visión de los padres del niño \\ hospitalizado \\ Postoperative pain management: view of the hospitalized children's parents
}

Larissa Domingas Grispan e Silva ${ }^{1}$

Mauren Teresa Grubisich Mendes Tacla²

Edilaine Giovanini Rossetto ${ }^{3}$

\section{RESUMO}

Considerando os efeitos deletérios da dor pós-operatória na criança e seu direito a receber alívio, sentiu-se a necessidade de estudar esse tema. Pesquisa qualitativa desenvolvida na unidade pediátrica de um hospital público de Londrina - Paraná, visando investigar a percepção dos pais quanto ao manejo da dor pós-operatória pela equipe de enfermagem e seu envolvimento neste processo. Foram entrevistados 10 familiares que acompanhavam crianças submetidas a cirurgias. Os dados foram agrupados em dois temas: caracterização do manejo da dor pós-operatória e estratégias adotadas para o alívio da dor pós-operatória. A terapia farmacológica foi mencionada como principal método utilizado pela equipe para analgesia. Quanto à atuação dos pais, referiram o uso de estratégias não farmacológicas como: distração, brinquedos, entre outros. 0 tratamento farmacológico é supervalorizado pelos profissionais e pelos pais. Técnicas não farmacológicas são extremamente úteis, porém, é necessário incentivar os pais a participar ativamente no manejo da dor pós-operatória de seus filhos.

Palavras-chave: Dor. Criança. Enfermagem Pediátrica. Família

\begin{abstract}
Considering the harmful effects of the postoperative pain on children and their right to get relief, there is a need to research this subject. Qualitative study developed at a pediatric unit of a public hospital in Londrina-Paraná, aims to analyze the parent's perception about the postoperative pain management by the nursing team and their involvement in this process. Ten parents of children that were submitted to surgeries were interviewed. Data were grouped in two themes: characterization of the postoperative pain management and strategies used to get relief of postoperative pain. Pharmacological therapy was considered the main method used by the nursing team to analgesia. Concerning the parent's actuation, they referred nonpharmacological strategies such as: distraction, use of toys, among others. Pharmacological treatment is overestimated by professionals and parents. Non-pharmacological techniques have proved useful. However, it is necessary to encouraged the parents to participate in the pain management of their children.
\end{abstract}

Keywords: Pain. Child. Pediatric Nursing. Family.

\section{Resumen}

Estudio cualitativo desarrollado en la unidad pediátrica de un hospital público en Londrina-Paraná tuvo como objetivo conocer la percepción de los padres en el manejo del dolor post-operatorio por parte del equipo de enfermería y su relación en este proceso. Fueron entrevistados 10 padres que acompañaban niños sometidos a cirugías. Los datos fueron agrupados en dos temas: caracterización del manejo del dolor post-operatorio y estrategias adoptadas para el alivio del dolor post-operatorio. La terapia farmacológica fue mencionada como el principal método utilizado para analgesia por parte del equipo de enfermería. Sobre la actuación de los padres, ellos mencionaron el uso de estrategias nofarmacológicas como: distracción, uso de juguetes, entre otros. El tratamiento farmacológico es súper valorizado por los profesionales e por los padres. Las técnicas nofarmacológicas se mostraron extremadamente útiles, sin embargo es necesario que los padres sean estimulados a participar activamente en el manejo del dolor de sus hijos.

Palabras clave: Dolor. Niño. Enfermería pediátrica. Familia

\footnotetext{
${ }^{1}$ Enfermeira. Residente de Enfermagem em Saúde da Criança - Universidade Estadual de Londrina - PR e pós-graduanda em Enfermagem com Ênfase em Pediatria - Faculdades Pequeno Príncipe - Curitiba - PR. Brasil. E-mail: lali_grispan@hotmail.com, ${ }^{2}$ Enfermeira. Doutora em Enfermagem. Professora Adjunta e Vicecoordenadora da Residência em Saúde da Criança do Departamento de Enfermagem da Universidade Estadual de Londrina -Londrina- PR. Brasil. E-mail: mtacla@sercomtel.com.br, ${ }^{3}$ Doutoranda em Enfermagem. Professora Assistente e Coordenadora da Residência em Enfermagem Neonatal do Departamento de Enfermagem da Universidade Estadual de Londrina - Londrina-PR. Brasil. E-mail: ediluiz@sercomtel.com.br
} 


\section{INTRODUÇÃO}

Durante a infância, muitas crianças são submetidas a procedimentos cirúrgicos. Toda cirurgia implica lesões de tecidos, manipulação de estruturas e órgãos, sendo a dor uma consequência natural desse processo, que pode, porém, ser minimizada. 0 período pós-operatório (PO), tão comum em uma unidade pediátrica, pode ser vivenciado pela criança de forma menos traumática se os profissionais responsáveis pelo seu cuidado estiverem sensibilizados para a importância da avaliação e alívio da dor e conhecerem estratégias adequadas para o seu tratamento. ${ }^{1}$

A dor prejudica a recuperação do paciente. Por outro lado, o alívio da dor pós-operatória promove: diminuição das complicações pulmonares, preservação da função miocárdica, mobilização precoce, menor incidência de tromboembolismo, atenuação da resposta ao estresse, redução do tempo de internação e conforto para o paciente. ${ }^{2}$

A importância do manejo da dor aguda vem sendo valorizada à medida que os benefícios aos pacientes são alcançados. Entre eles, pode-se destacar a mobilização precoce, a diminuição do período de internação e a consequente redução de custos. ${ }^{2}$

0 controle da dor aguda pós-operatória é de responsabilidade do anestesista, do cirurgião e da equipe de enfermagem. Esta última deve, na sala de recuperação pósanestésica e na unidade de internação, avaliar a intensidade da dor, aplicar fármacos e técnicas de analgesia e realizar intervenções não farmacológicas, além de propiciar conforto ao paciente. ${ }^{5}$

Os autores alertam que, ao cumprir o dever ético e legal de amenizar o sofrimento ao controlar a dor pósoperatória, "o profissional capaz e consciente, pode e deve, sempre, empregar todos os meios e recursos adequados que conheça e tenha a seu alcance". 5:6

0 alívio da dor possibilita à criança condições para restabelecer-se adequadamente, o que atende aos princípios da humanização e da ética que deve permear o cuidado do enfermeiro. ${ }^{6}$

0 Conselho Nacional dos Direitos da Criança e do Adolescente, em sua resolução $n^{0} .41$, dispõe sobre os Direitos da Criança e do Adolescente Hospitalizados, evidenciando em seu artigo $7^{\circ}$ que o paciente tem "direito a não sentir dor, quando existem meios para evitá-la"?:16319 Nesse mesmo sentido, convém ressaltar que o paciente tem direito a decidir o nível de dor que está disposto a tolerar, escolher seu método preferido de controle da dor, além de ser atendido por uma equipe de saúde competente para proporcionar o alívio adequado da dor. ${ }^{2}$ No caso da criança pequena e/ou sem habilidade verbal, esse papel deve ser exercido por seus familiares.

0 enfermeiro exerce um papel importante no manejo da dor, fornecendo informações e orientando o paciente e a família com intuito de aliviar o estresse e o medo pelo desconhecido. Lamentavelmente, muitas crianças ainda não recebem tratamento adequado para o alívio da dor no período pós-operatório, mesmo em situaç̃̃es em que a analgesia poderia ser feita com relativa facilidade e com ampla margem de segurança, não havendo, portanto, razões para o não tratamento dos quadros álgicos neste período. ${ }^{4}$

0 manejo adequado da dor deve ser uma prioridade no planejamento terapêutico de pacientes pediátricos, sendo que a dor tratada de maneira preventiva ou o mais precocemente possível é de mais fácil manipulação do que aquela já estabelecida ou intensa. ${ }^{8}$

A literatura ressalta que, infelizmente, a dor é muitas vezes encarada como algo inevitável, principalmente no período pós-operatório. ${ }^{1}$ No entanto, as enfermeiras continuam restritas a medidas farmacológicas para o seu alívio e tendem à subadministração de analgésicos para controlar a dor aguda nesse período. Estudo indica que, quando questionadas, as enfermeiras priorizavam outras atividades e que, às vezes, banalizavam as experiências de dor pós-operatória dos pacientes, fazendo-as parecer sem importância. Identificaramse também nas enfermeiras pesquisadas atitudes que demonstravam a falta de valorização dos sinais de dor, pois estes foram considerados menos importantes quando comparados a outras atividades tais como: administração de medicação, verificação de sinais vitais, troca de curativos, entre

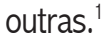

Muitas vezes, o controle inadequado da dor está relacionado à falta de critérios e métodos de avaliação e registro. Há necessidade de se conhecer e registrar adequadamente as características da dor pós-operatória, tais como: local, qualidade, intensidade, início, duração, fatores de piora ou melhora, fatores associados, duração e magnitude do alívio obtido. Dessa forma, é possivel compreender o quadro doloroso, detectar complicações e realizar adequação do tratamento. ${ }^{9}$

0 profissional de saúde, ciente do caráter multidimensional da experiência dolorosa, deve atentar para o fato de que o indivíduo seja, então, visto como autoridade sobre a sua dor. ${ }^{4}$ Ao perguntar às crianças sobre a dor, é importante lembrar que elas podem negá-la por ter medo que o tratamento seja pior que a própria dor ou por acreditarem merecer uma punição por algum erro. Elas também podem negar a dor para uma pessoa estranha, mas rapidamente a admitem para os pais, como uma indicação válida de dor. ${ }^{10}$

A criança deve saber que sua dor está sendo levada a sério e que seus pais, enfermeiros e médicos farão todo o possível para aliviá-la. Ela também deve ser informada que o tratamento da dor não será pior que a dor em si. ${ }^{11}$

Embora avaliar e mensurar a dor não sejam tarefas fáceis, esses procedimentos devem se tornar rotineiros para os enfermeiros, os quais devem registrar essas informações no prontuário da criança, para que as devidas providências de alívio da dor possam ser implementadas. 
A participação dos pais na avaliação e tratamento da dor pós-operatória das crianças também é de extrema importância. A família deve envolver-se no processo de avaliação da dor fornecendo informações como mudanças de comportamento e estado emocional do paciente. Os pais, em geral, conhecem o comportamento usual de seus filhos diante da dor e podem identificar comportamentos específicos de cada criança e devem ser orientados e incentivados a participar ativamente na identificação e na avaliação da resposta de seus filhos às intervenções.

Considerando os efeitos deletérios da dor pósoperatória na criança e seu direito a receber alívio, entendemos a necessidade de estudar aspectos que merecem ser melhor conhecidos a respeito desse tema. Tendo em vista que a percepção não só da criança, mas também da família, são instrumentos valiosos que refletem como a equipe trabalha com o manejo da dor pediátrica, este estudo tem o objetivo de investigar a percepção dos pais quanto ao manejo da dor pósoperatória por parte da equipe de enfermagem e seu envolvimento neste processo. Os dados obtidos poderão contribuir para a implementação de estratégias de aprimoramento desse cuidado.

\section{METODOLOGIA}

Estudo é descritivo-exploratório, de abordagem qualitativa, pois visa responder às questões particulares, considerando como sujeitos do estudo pessoas pertencentes a determinada condição social, com suas crenças, valores e significados que, nesta pesquisa, são os pais de crianças hospitalizadas submetidas a cirurgia. ${ }^{12}$

0 campo de pesquisa foi a unidade de internação pediátrica de um hospital universitário de nível terciário, de natureza pública, localizado em Londrina - PR, com 34 leitos pediátricos, dos quais 6 são destinados a pacientes cirúrgicos. A referida unidade adota o sistema de internação conjunta e tem a mãe como o acompanhante mais frequente.

0 projeto de pesquisa foi submetido à apreciação $e$ aprovado pelo Comitê de Ética em Pesquisa Envolvendo Seres Humanos da Universidade Estadual de Londrina (UEL), de acordo com o processo n. 099/07 de 19/06/ 2007.

A escolha do tema foi motivada pelo interesse dos autores em relação ao assunto associado à falta de sistematização do manejo da dor na realidade observada. É importante salientar que, no período da pesquisa, a avaliação da dor como $5^{\circ}$ sinal vital estava sendo implementada no hospital onde o estudo foi realizado, sendo oferecidos treinamentos e capacitações aos colaboradores.
Os sujeitos da pesquisa foram 10 membros das famílias que acompanhavam as crianças internadas que foram submetidas a cirurgias de médio e grande porte há, no mínimo, dois dias. As cirurgias podem ser classificadas como de pequeno, médio e grande porte, segundo o risco cardiológico, ou seja, a probabilidade de perda de fluido e sangue durante sua realização, e também considerando o tempo do ato cirúrgico. ${ }^{13}$ A maioria dos acompanhantes $(n=8)$ eram mães das crianças e uma pequena parte pais $(n=2)$. Em ambos os sexos, a idade variou de 25 a 50 anos. Grande parte dos entrevistados não havia completado o ensino fundamental. Quando questionados sobre experiências anteriores com hospitalização, sete pais referiram já ter vivido essa situação com esta ou outra criança da família.

A opção pelo pós-operatório de cirurgias desse tipo fundamenta-se na duração mais longa do ato cirúrgico e na maior manipulação de órgãos e estruturas com maior probabilidade de causarem dor moderada ou forte. Também demandam um período de hospitalização mais prolongado e possibilitam aos pais acompanhantes inúmeras oportunidades de vivenciar o processo de manejo da dor pós-operatória de seus filhos. Seguindo este raciocínio, as entrevistas foram realizadas a partir do segundo dia de pósoperatório, pois os sujeitos teriam mais informações a relatar.

A coleta dos dados ocorreu entre os meses de agosto e setembro de 2007 e foram realizadas desde $02^{\circ} \mathrm{PO}$ até 0 $5^{\circ} \mathrm{PO}$, sendo que neste estudo consideramos como pósoperatório imediato (POI) o período de 24 horas contadas a partir do horário de término da cirurgia e as 24 horas seguintes como $1^{\circ} \mathrm{PO}$ e, sucessivamente, a cada 24 horas, $2^{\circ} \mathrm{PO}, 3^{\circ} \mathrm{PO}, 4^{\circ} \mathrm{PO}$ e $5^{\circ} \mathrm{PO}$.

Em relação às crianças hospitalizadas, seis eram meninos e quatro meninas, com idades entre 1 ano e 11 meses e 12 anos e 2 meses. Em dois casos as crianças foram submetidas a cirurgias ortopédicas, e os oito restantes foram procedimentos realizados pela cirurgia pediátrica, tais como: apendicectomia, toracoscopia e correção de hipospádia.

Os dados foram obtidos com a utilização de entrevista semiestruturada, gravada, com a devida autorização do entrevistado, após a assinatura do Termo de Consentimento Livre e Esclarecido. Previamente, foram realizadas duas entrevistas-piloto para adequação do instrumento de coleta de dados. Convém destacar que o estudo foi realizado de acordo com as normas da Resolução 196/96 do Conselho Nacional de Saúde, de 10 de outubro de 1996. ${ }^{14}$

As entrevistas gravadas foram transcritas e identificadas com números de 1 a 10, em ordem cronológica à sua realização. Depois de repetidas leituras, para apreensão das falas dos sujeitos, os dados foram detalhadamente analisados e organizados em categorias. 


\section{RESULTADOS E DISCUSSÃO}

A categorização dos dados nos levou à formulação de dois núcleos temáticos: caracterização do manejo da dor pósoperatória e estratégias adotadas para o alívio da dor pósoperatória, apresentadas a seguir.

\section{Caracterização do manejo da dor pós-operatória}

Todos os entrevistados classificaram como boa ou ótima a atuação da equipe de enfermagem no alívio da dor pósoperatória de seus filhos, como pode ser observado na fala abaixo:

Ela está sendo bem tratada até agora. ... Não deixaram ela ficar com dor nem um pouquinho. (E10)

A terapia farmacológica foi mencionada por todos os sujeitos como principal método para o alívio da dor, e o uso de medicamentos foi citado inúmeras vezes. Este fato pode ser confirmado pelo relato abaixo:

... se ela reclama (de dor), elas (equipe de enfermagem) vêm rapidinho com o remédio. (E3)

A melhora após a administração da medicação foi relatada por grande parte dos pais, fato este que evidencia uma melhor conscientização dos profissionais médicos a respeito da prescrição adequada de analgésicos durante o período pósoperatório, corroborando a afirmação encontrada na literatura de que o profissional da saúde pode não garantir a ausência completa da dor após a cirurgia, mas pode e deve aliviar e controlar essa dor, tornando-a pelo menos suportável, para facilitar a recuperação do paciente, e evitando deixar lembranças desagradáveis. ${ }^{5}$

Vale destacar que na instituição estudada não há uma padronização quanto à administração de analgésicos, podendo estes serem prescritos a critério médico com intervalos regulares (de $8 \mathrm{em} 8$ horas, de $6 \mathrm{em} 6$ horas ou de 4 em 4 horas) ou ainda somente quando a criança apresenta dor (se necessário). 0 que se observa na prática é que nos primeiros dias do período P0, de acordo com o porte da cirurgia, a maior parte das crianças recebe analgesia em horários fixos, o que é substituído gradativamente conforme a reação da criança em relação à dor para o esquema "se necessário".

A medicação "se necessário", porém, é administrada somente quando a criança refere dor, ou seja, espera-se que o quadro álgico se instale, o que permite que a criança sinta dor. A realidade revela ainda a não utilização de métodos não farmacológicos durante o manejo da dor, refletindo a não valorização do profissional de enfermagem no que se refere à aplicação de tais estratégias.

Apenas uma pequena parte dos acompanhantes relatou que a medicação prescrita a princípio foi insuficiente para aliviar a dor pós-operatória de seu filho, tendo de ser reajustada para obter a eficácia desejada. Este fato é demonstrado pelo relato a seguir:

...Quando ele veio da UTI depois da cirurgia, ele sentiu bastante dor, porque deixaram ele com um remédio fraco, mas eu conversei com a enfermeira e ela pediu para o médico receitar um mais forte, que foi o que adiantou, e agora ele já está bem melhor... (E 1)

A literatura traz exemplos de estudos que examinaram o padrão de medicação da dor em crianças, comparado aos adultos, e indicaram achados de que as crianças foram submedicadas para dor. ${ }^{10}$ Outros autores também afirmam que a dor do paciente pediátrico é normalmente subestimada e o subtratamento acontece rotineiramente em vários serviços. ${ }^{4}$ Este fato se deve, em parte, a conceitos divulgados há até pouco tempo de que os recém-nascidos, lactentes e as crianças menores não teriam maturidade neurológica para conduzir, de forma adequada, os estímulos dolorosos, devido à mielinização incompleta do sistema nervoso. ${ }^{3}$

Havia também a crença de que esses pacientes não teriam capacidade de armazenar em sua memória essas experiências dolorosas. ${ }^{3}$ Sabe-se, atualmente, que esses conceitos são totalmente incorretos e que as vias aferentes e os centros corticais e subcorticais, necessários à percepção da dor, estão bem desenvolvidos já nas etapas finais da gestação. Estudos indicam que, a partir da $20^{a}$ semana de gestação, os recém-nascidos têm considerável maturidade do sistema periférico, espinhal e supraespinhal de condução da dor, reagindo a injúrias teciduais com respostas autonômicas, teciduais e hormonais de estresse..$^{15}$

Outro estudo que contradiz a hipótese de que as crianças sentem menos dor que os adultos demonstra que, quanto menor a idade, menores são os limiares de dor, e limiares menores significam sentir mais dor. ${ }^{16}$ Neste caso, estímulos cuja intensidade normalmente não causariam dor, em consequência dos baixos limiares, tornam-se dolorosos.

Este fato deixa explíito que medidas que elevam os limiares (analgésicos e medidas não farmacológicas) devem receber maior atenção por parte dos profissionais que trabalham com essa faixa etária.

Ainda em relação ao tratamento farmacológico no alívio da dor pós-operatória, uma pequena parte dos pais relatou que algumas vezes seus filhos sentiram dor entre uma administração de medicamentos e outra. Nesse sentido, é preciso enfatizar que a dor deve ser tratada antes de sua manifestação, tendo em vista que seus efeitos deletérios dificultam a recuperação pósoperatória do paciente. ${ }^{3} 0$ mesmo autor coloca ainda que não se deve permitir que o paciente tente tolerar a dor, aguardando que ela diminua sozinha; deve-se, sim, ao menor sinal de sua 
chegada, medicá-lo ou orientá-lo a receber a medicação analgésica prescrita.

A dor é um sintoma muito desconfortável no período pós-operatório, e, apesar de serem claras as necessidades de controle da dor e de protocolos antiálgicos, muitos pacientes sofrem com a dor após uma cirurgia. A dor deve ser sempre tratada, principalmente a que é sentida no período pósoperatório. ${ }^{11}$

A dor não tratada traz prejuízos como o atraso do processo de cura dos tecidos e a recuperação do paciente; causa ansiedade, depressão e irritabilidade; pode trazer problemas relativos à alimentação e ao sono; torna a criança medrosa; altera a estabilidade respiratória, cardiovascular e metabólica; produz alterações hidroeletrolíticas, bioquímicas e estruturais no sistema nervoso central; aumenta o tempo de internação, a morbidade e a mortalidade; além de afetar futuras experiências de dor no indivíduo., ${ }^{3,4,6}$

\section{Estratégias adotadas para 0 alívio da dor pós- operatória}

Quando os sujeitos foram questionados a respeito das oportunidades vivenciadas por eles para contribuir no alívio da dor pós-operatória de seus filhos, a grande maioria das respostas indicou o uso de estratégias não farmacológicas.

A administração de medicamentos é a base para o alívio efetivo da dor, mas em virtude de a dor ser mais que meramente uma experiência sensorial, outros métodos de alívio são parte importante do cuidado ao paciente pediátrico e os métodos não farmacológicos devem fazer parte do tratamento para o alívio da dor. Os pais devem receber mais orientações quanto ao uso de estratégias não farmacológicas no manejo da dor pósoperatória de seus filhos hospitalizados, fato este não mencionado pelos entrevistados.

As medidas adotadas pelos pais entrevistados visando ao alívio da dor de seus filhos fazem parte do senso comum e são aprendidas no convívio familiar e social, não tendo sido indicadas ou sugeridas pela equipe de enfermagem durante a hospitalização. Estudo sobre o manejo da dor pós-operatória em crianças realizado em unidades de internação pediátrica de três hospitais de Londrina revelou que o enfermeiro pouco prescreve métodos não farmacológicos para o alívio da dor e que os mesmos são pouco utilizados por toda equipe de enfermagem. ${ }^{1}$ As terapêuticas utilizadas para o alívio da dor não podem mais ficar restritas ao uso de fármacos, principalmente, tratando-se de crianças. Elas precisam tanto da medicação, quando necessária, quanto de brincadeiras, distração e, principalmente, da atenção da equipe de saúde., ${ }^{2,11}$

As medidas não farmacológicas utilizadas pelos pais para aliviar a dor de seus filhos durante o período de internação são descritas no Quadro 1. É importante salientar que cada um dos pais forneceu mais de uma resposta.

Osvalores são apresentados individualmente de acordo coma frequência com queforam relatados esomados ao final $(n=58)$.
Durante a análise dos resultados, não foram encontradas diferenças significativas quanto às estratégias utilizadas pelos pais no manejo da dor de seus filhos quando considerávamos o fato de possuírem ou não experiências anteriores com hospitalização dessa ou de outra criança; isto é, os dois grupos agiram de forma semelhante.

Quadro 1. Medidas não farmacológicas utilizadas pelos pais para o alívio da dor pós-operatória de seus filhos.

\begin{tabular}{|lc|}
\hline \multicolumn{1}{|c}{$\begin{array}{c}\text { Estratégias não } \\
\text { farmacológicas }\end{array}$} & Múltiplas respostas \\
\cline { 2 - 2 } & Frequência \\
\hline Distração & 9 \\
Brinquedos & 8 \\
Acalmar/alegrar/encorajar & 8 \\
Conversar/ explicar & 7 \\
Ficar/ estar perto & 6 \\
Carinho & 5 \\
Pegar no colo/na mão & 4 \\
TV/ filme/ desenhos & 3 \\
Deambulação & 2 \\
Atenção dedicada à criança & \\
pela enfermeira/solicitar a & 2 \\
presença da enfermeira & 1 \\
Livros & 1 \\
Pedir a colaboração da criança & 1 \\
Ajudar/participar do cuidado à & 58 \\
criança & \\
Massagem & \\
\hline Total & \\
\hline
\end{tabular}

No Quadro 1 observamos que a maioria dos acompanhantes utilizou a distração como forma de aliviar a dor pós-operatória de seus filhos. A distração pode ser entendida como a centralização em outras coisas que não seja a dor. A sensação de dor não é eliminada com esta técnica, porém se torna mais tolerável quando é substituída por outro pensamento, o que proporciona ao paciente um senso de controle sobre a dor. Propor atividades prazerosas, mesmo quando o paciente está sentindo dor, pode diminuir muito a sua atenção do foco doloroso e, com isso, aumentar o limiar de dor. ${ }^{17}$

0 termo distração foi utilizado pelos pais sem 0 conhecimento teórico desta técnica, mas como uma forma de fazer com que seu filho tivesse a sua atenção focada em outra coisa que não a sua dor.

Os depoimentos a seguir evidenciam a informação acima, relatando que atividades recreativas distraem a criança e fazem com que ela se sinta mais calma. 
No Quadro 1 observamos que a maioria dos acompanhantes utilizou a distração como forma de aliviar a dor pós-operatória de seus filhos. A distração pode ser entendida como a centralização em outras coisas que não seja a dor. A sensação de dor não é eliminada com esta técnica, porém se torna mais tolerável quando é substituída por outro pensamento, o que proporciona ao paciente um senso de controle sobre a dor. Propor atividades prazerosas, mesmo quando o paciente está sentindo dor, pode diminuir muito a sua atenção do foco doloroso e, com isso, aumentar o limiar de dor. ${ }^{17}$

0 termo distração foi utilizado pelos pais sem 0 conhecimento teórico desta técnica, mas como uma forma de fazer com que seu filho tivesse a sua atenção focada em outra coisa que não a sua dor.

Os depoimentos a seguir evidenciam a informação acima, relatando que atividades recreativas distraem a criança e fazem com que ela se sinta mais calma.

... com essa TV aqui no quarto ele também assiste filme e desenhos. Acho que ele se distrai um pouco e esquece um pouco da dor. (E 1)

Trouxeram uns brinquedinhos pra ele ontem, ele brincou e isso ajudou bastante. Ele fica mais entretido e esquece do probleminha dele. (E 8)

A presença da televisão em algumas enfermarias, permitindo que a criança assista a filmes e desenhos animados, também foi relatada por uma parte dos entrevistados. 0 uso de brinquedos, citado pela maioria dos entrevistados, foi considerado por eles uma maneira eficiente para aliviar a dor no período pós-operatório.

0 objetivo da recreação é manter ou restituir a integridade do paciente. 0 brinquedo é uma atividade importante durante a infância e deve ser considerado não apenas como uma diversão e entretenimento, mas também como um trabalho da criança em que ela se desenvolve emocional, social e intelectualmente. Através do brinquedo, a criança expressa seus sentimentos durante a hospitalização e interage com a equipe. ${ }^{18}$

A criança hospitalizada continua sendo criança, e as crianças, mesmo doentes, têm necessidade de brincar. 0 brinquedo terapêutico desenvolve, em parte, aspectos normais do cotidiano da criança e, por esta razão, deve ser utilizado na assistência a clientes nessa faixa etária para tentar tornar o ambiente hospitalar menos estressante e traumático. ${ }^{18}$

É importante ressaltar que na unidade pediátrica do hospital onde foi realizado este estudo, existe uma brinquedoteca, onde as crianças têm acesso a diversos brinquedos, para todas as idades. Para as crianças impossibilitadas de ir até a sala de brinquedos, a funcionária responsável - a recreacionista - ou os próprios pais podem escolher alguns brinquedos e levar até as enfermarias onde as crianças se encontram. Esse fato talvez explique o alto número de relatos a respeito do brinquedo como estratégia de alívio da dor pós-operatória.

A presença dos pais junto à criança durante o período de internação também foi citada como fator benéfico para o alívio da dor pós-operatória. Essa afirmação pode ser verificada na seguinte fala:

Ás vezes quando eu estou um pouquinho longe, ela já chama pra ir perto, pra segurar na mão dela. Isso dá uma força pra ela, ajuda bastante... (E 6)

A proposta da permanência de um acompanhante no hospital enfatiza a necessidade da colaboração da família no processo de recuperação da saúde da criança por meio do apoio emocional e segurança sentida pela criança por ter ao seu lado alguém de sua confiança. Pais e equipe de enfermagem têm pelo menos um objetivo comum: o restabelecimento da saúde da criança; por isso, encorajados a ficar com seus filhos durante a hospitalização, os pais tornam-se mais um agente do processo do cuidado. Ter os pais ou outras pessoas queridas por perto é o melhor tratamento psicológico para a dor das crianças, pois, dessa forma, elas se sentem mais seguras e protegidas. ${ }^{11}$

Atitudes como acalmar, alegrar e encorajar, além de conversar e explicar à criança o que está acontecendo com ela, também foram citadas pelos entrevistados como oportunidades vivenciadas por eles para contribuir no alívio da dor pósoperatória de seus filhos, como observado no relato que se segue:

Eu converso com ela também, explico que é preciso fazer para ir embora logo e ela aceita. Ela compreende tudo... (E 6)

As crianças necessitam de informações simples sobre 0 que está acontecendo ou vai acontecer com elas. Não se deve mentir sobre procedimentos dolorosos nem usar ameaças, pois as mentiras levam as crianças a suspeitar de tudo e de todos, e ameaças as transformam em crianças medrosas. A explicação deve ser feita com calma e repetida, se necessário. É importante que ela saiba que quem explica entende o que ela vai sentir. ${ }^{11}$

Portanto, os enfermeiros que trabalham em unidades pediátricas devem examinar e refletir sobre o modo como envolvem os pais no cuidado à criança com dor e aplicar estratégias para que esse envolvimento se dê de forma ativa, pois os pais não querem ser apenas expectadores, mas atuar de forma efetiva no manejo da dor de seu filho. Agindo assim os enfermeiros melhorariam a qualidade da hospitalização para a criança e seus pais. Evidencia-se, então, que a equipe deve se mostrar disposta e ter empatia para que o manejo da dor pós- 
No Quadro 1 observamos que a maioria dos acompanhantes utilizou a distração como forma de aliviar a dor pós-operatória de seus filhos. A distração pode ser entendida como a centralização em outras coisas que não seja a dor. A sensação de dor não é eliminada com esta técnica, porém se torna mais tolerável quando é substituída por outro pensamento, o que proporciona ao paciente um senso de controle sobre a dor. Propor atividades prazerosas, mesmo quando o paciente está sentindo dor, pode diminuir muito a sua atenção do foco doloroso e, com isso, aumentar o limiar de dor. ${ }^{17}$

0 termo distração foi utilizado pelos pais sem 0 conhecimento teórico desta técnica, mas como uma forma de fazer com que seu filho tivesse a sua atenção focada em outra coisa que não a sua dor.

Os depoimentos a seguir evidenciam a informação acima, relatando que atividades recreativas distraem a criança e fazem com que ela se sinta mais calma.

com essa TV aqui no quarto ele também assiste filme e desenhos. Acho que ele se distrai um pouco e esquece um pouco da dor. (E 1)

Trouxeram uns brinquedinhos pra ele ontem, ele brincou e isso ajudou bastante. Ele fica mais entretido e esquece do probleminha dele. (E 8)

A presença da televisão em algumas enfermarias, permitindo que a criança assista a filmes e desenhos animados, também foi relatada por uma parte dos entrevistados. 0 uso de brinquedos, citado pela maioria dos entrevistados, foi considerado por eles uma maneira eficiente para aliviar a dor no período pós-operatório.

0 objetivo da recreação é manter ou restituir a integridade do paciente. 0 brinquedo é uma atividade importante durante a infância e deve ser considerado não apenas como uma diversão e entretenimento, mas também como um trabalho da criança em que ela se desenvolve emocional, social e intelectualmente. Através do brinquedo, a criança expressa seus sentimentos durante a hospitalização e interage com a equipe. ${ }^{18}$

A criança hospitalizada continua sendo criança, e as crianças, mesmo doentes, têm necessidade de brincar. 0 brinquedo terapêutico desenvolve, em parte, aspectos normais do cotidiano da criança e, por esta razão, deve ser utilizado na assistência a clientes nessa faixa etária para tentar tornar 0 ambiente hospitalar menos estressante e traumático. ${ }^{18}$

É importante ressaltar que na unidade pediátrica do hospital onde foi realizado este estudo, existe uma brinquedoteca, onde as crianças têm acesso a diversos brinquedos, para todas as idades. Para as crianças impossibilitadas de ir até a sala de brinquedos, a funcionária responsável - a recreacionista - ou os próprios pais podem escolher alguns brinquedos e levar até as enfermarias onde as crianças se encontram. Esse fato talvez explique o alto número de relatos a respeito do brinquedo como estratégia de alívio da dor pós-operatória.

A presença dos pais junto à criança durante o período de internação também foi citada como fator benéfico para 0 alívio da dor pós-operatória. Essa afirmação pode ser verificada na seguinte fala:

Ás vezes quando eu estou um pouquinho longe, ela já chama pra ir perto, pra segurar na mão dela. Isso dá uma força pra ela, ajuda bastante... (E 6)

A proposta da permanência de um acompanhante no hospital enfatiza a necessidade da colaboração da família no processo de recuperação da saúde da criança por meio do apoio emocional e segurança sentida pela criança por ter ao seu lado alguém de sua confiança. Pais e equipe de enfermagem têm pelo menos um objetivo comum: o restabelecimento da saúde da criança; por isso, encorajados a ficar com seus filhos durante a hospitalização, os pais tornam-se mais um agente do processo do cuidado. Ter os pais ou outras pessoas queridas por perto é o melhor tratamento psicológico para a dor das crianças, pois, dessa forma, elas se sentem mais seguras e protegidas. ${ }^{11}$

Atitudes como acalmar, alegrar e encorajar, além de conversar e explicar à criança o que está acontecendo com ela, também foram citadas pelos entrevistados como oportunidades vivenciadas por eles para contribuir no alívio da dor pósoperatória de seus filhos, como observado no relato que se segue:

Eu converso com ela também, explico que épreciso fazer para ir embora logo e ela aceita. Ela compreende tudo... (E6)

As crianças necessitam de informações simples sobre o que está acontecendo ou vai acontecer com elas. Não se deve mentir sobre procedimentos dolorosos nem usar ameaças, pois as mentiras levam as crianças a suspeitar de tudo e de todos, e ameaças as transformam em crianças medrosas. A explicação deve ser feita com calma e repetida, se necessário. É importante que ela saiba que quem explica entende o que ela vai sentir.11

Portanto, os enfermeiros que trabalham em unidades pediátricas devem examinar e refletir sobre o modo como envolvem os pais no cuidado à criança com dor e aplicar estratégias para que esse envolvimento se dê de forma ativa, pois os pais não querem ser apenas expectadores, mas atuar de forma efetiva no manejo da dor de seu filho. Agindo assim os enfermeiros melhorariam a qualidade da hospitalização para a criança e seus pais. Evidencia-se, então, que a equipe deve se mostrar disposta e ter empatia para que o manejo da dor pósoperatória seja feito de maneira adequada, principalmente nesta faixa etária. 


\section{CONCLUSÕES}

Mesmo com diversos estudos relacionados ao alívio da dor na criança, muitos profissionais ainda não se conscientizaram a respeito da necessidade e dos benefícios do tratamento adequado da dor, para o paciente e para a própria equipe de saúde, principalmente àquela sentida no período pós-operatório.

Na visão dos pais, a dor das crianças foi, de maneira geral, bem atendida. Entretanto, a literatura mostra que, muitas vezes, a criança, talvez pelo seu desenvolvimento cognitivo, tem sua dor subestimada e julgada por aquele que the presta assistência, sofrendo assim, desnecessariamente, as consequências da dor não tratada de forma adequada. Tal consideração frequentemente referida na literatura pode ser uma resultante entre os meios disponíveis para o alívio da dor versus aqueles aplicados apropriadamente na prática, e este conhecimento não pertence ao grupo de pais que não profissionais da saúde.

0 tratamento farmacológico, embora de fundamental importância, é culturalmente supervalorizado pelos profissionais e também pelos pais, fato comprovado pelas falas obtidas durante a pesquisa.

A cultura da medicalização limita a ação do profissional e principalmente da família que, frequentemente, não é incluída no tratamento.

As técnicas não farmacológicas utilizadas pelos acompanhantes e relatadas nas entrevistas se mostram extremamente úteis, mas eles as utilizam espontaneamente, sem direcionamento ou incentivo dos profissionais. Este fato faz com que os pais não se sintam incluídos no manejo da dor de seus filhos. É necessário que os pais e acompanhantes sejam orientados e motivados pela equipe de enfermagem a participar ativamente no manejo da dor de seus filhos após a cirurgia. 0 manejo da dor requer conhecimentos técnicos, mas também empatia por parte do profissional, já que, na maioria das vezes, a tecnologia e as intervenções que possibilitam o alívio da dor estão acessíveis ao enfermeiro.

Os dados obtidos indicam que, mesmo com a implementação da avaliação sistematizada da dor como quinto sinal vital no hospital em que este estudo foi realizado, muito ainda se pode avançar para aprimorar o manejo da dor pósoperatória pela equipe de enfermagem. É nosso dever alertar e incentivar enfermeiros e familiares quanto à importância do tratamento eficaz da dor na criança e o papel de cada um nesse cenário, somando esforços para que a criança não sofra desnecessariamente.

\section{REFERÊNCIAS}

1. Tacla MTGM. Cuidado à criança com dor pós-operatória: experiências de enfermeiras pediatras [tese de doutorado]. Ribeirão Preto (SP): Escola de Enfermagem de Ribeirão Preto / USP; 2006.

2. Bernardo CLE. 0 papel da enfermagem. In: Drummond JP. Dor aguda: fisiopatologia, clínica e terapêutica. São Paulo(SP): Atheneu; 2000. p. 171-210.
3. Andrade MP. Dor pós-operatória: conceitos básicos de fisiopatologia e tratamento. Rev Soc Bras Est Dor 2000 abr/maio/jun; 2 (2): 7-14.

4. Barbosa SMM, Guinsburg R. Dor de acordo com as faixas etárias pediátricas. In: Teixeira MJ, editor. Dor: contexto interdisciplinar. Curitiba (PR): Ed Maio; 2003. p. 536-45.

5. Posso IP, Costa DSP. De quem é a responsabilidade no tratamento da dor pós-operatória? Âmbito Hospitalar 2005 jan/fev; 17 (170): 3-8.

6. Persegona, KR; Zagonel, IPS. A relação intersubjetiva entre o enfermeiro e a criança com dor na fase pós-operatória no ato de cuidar. Esc Anna Nery Rev Enferm 2008 set; 12 (3): 430-6.

7. Resolução $n^{0} 41$, de 13 de outubro de 1995. Dispõe sobre os direitos da criança e do adolescente hospitalizados. Diário Oficial da República Federativa da União, Brasília (DF), 17 out 1995: Seção 1: 16319-20.

8. Cavalcante V0, Teixeira MJ, Franco RA. Dor pós-operatória. Rev Simbidor 2000; 1 (1): 45-53.

9. Pimenta CAM. Controle da dor no pós-operatório. São Paulo (SP): Lemos Edit, 2002.

10. Hockenberry, MJ; Wilson D; Winkelstein ML. Wong Fundamentos de Enfermagem Pediátrica. $7^{0}$ ed. São Paulo(SP): Elsevier; 2006.

11. Claro MT. Dor em pediatria. In: Leão ER; Chaves L.D. Dor $-5^{\circ}$ sinal vital: intervenções de enfermagem. Curitiba (PR): Ed Maio; 2004. p. 207-18.

12. Bogdan R; Biklen S. Investigação qualitativa em educação: uma introdução à teoria e aos métodos. Porto (PT): Porto Ed; 1994.

13. Eagle KA, et al. Guideline for perioperative cardiovascular evaluation for non cardiac surgery. Circulation [periódico on line], 1996; [citado 21 set. 2007]. Disponível em http://www.joaopossari.hpg.ig.com.br/ classificacaocirurgica.htm

14. Resolução n. 196, de 10 out. 1996. Dispõe sobre as diretrizes e normas regulamentadoras de pesquisas em seres humanos. Inf Epidemiol SUS: 1996. Supl

15. Coeli SCM. Dor aguda na criança. In: Drummond JP.Dor aguda: fisiopatologia, clínica e terapêutica. São Paulo (SP):Atheneu; 2000. p. 151-70.

16. Duarte MA,Goulart EMA, Penna FJ. Limiar de dor e idade na infância e adolescência. J Pediatr 1999; 75 (4): 244-48.

17. Tengan SK. Tratamento psicológico da dor na infância. In: Teixeira MJ., editor. Dor: contexto interdisciplinar. Curitiba (PR): Ed Maio, 2003. p. 739-42.

18. Guareschi APDF; Martins LMM. Relacionamento multiprofissional X criança $X$ acompanhante: desafio para a equipe. Rev Esc Enferm USP 1997 dez; 31 (3): 423-36. 